\title{
Mulheres e RCC na América do Sul: uma revisão bibliográfica e um estudo de sites do Movimento de Renovação Carismática Católica
}

\author{
Cristiane Santos de Castro*
}

\begin{abstract}
Resumo: Neste trabalho, procuro analisar a posição da mulher no catolicismo especialmente na Renovação Carismática Católica (RCC) e nas novas comunidades a partir de uma revisão da bibliografia e também de dados coletados em sites desse movimento e dessas comunidades no Brasil e em outros países latinos da América do Sul. Baseada na análise da bibliografia sobre mulheres no catolicismo na América Latina, procuro avaliar em que medida a RCC tem favorecido a presença das mulheres nos espaços de liderança religiosa católica. 0 objetivo, portanto, é discutir se houve alterações na posição da mulher no catolicismo a partir do crescimento do movimento carismático. Complemento essa discussão bibliográfica com levantamento de dados disponíveis em sites da RCC de países da América do Sul contabilizando as mulheres em cargos de liderança no movimento e nas comunidades carismáticas, buscando também refletir como as relações de gênero da sociedade em geral podem influenciar ou determinar a forma como as mulheres se inserem ou atuam no movimento carismático nesses países.
\end{abstract}

Palavras-chave: mulheres, relações de gênero, catolicismo, Renovação Carismática Católica.

\section{Introdução}

A religião como instituição social muito contribuiu para a criação e a redefinição das identidades de gênero, influenciando as relações e representações de gênero não só no âmbito religioso, mas em todas as esferas sociais. No Brasil, histórica e culturalmente, tem se observado que, no imaginário coletivo a respeito das relações de gênero, a religião seria uma atividade atribuída às mulheres (THEIJE, 2002, entre outros autores). Considera-se, nessa concepção, que as mulheres possuem características que as tornariam mais aptas para as atividades religiosas. Além do mais, a religião caberia às mulheres por pertencerem ao domínio da esfera privada.

Por outro lado, as religiões tendem a sustentar que os papéis sociais são sagrados, sacralizando a crença de que homens e mulheres possuem papéis sociais diferentes que se complementariam: ao homem é delegada a autoridade sobre sua família e à mulher cabe o papel de subserviência para com o seu marido e o cuidado

\footnotetext{
* Graduanda em Ciências Sociais - UERJ.
} 
com os filhos. Dessa forma, o fato dos grupos religiosos atribuírem ao gênero masculino o papel de provedor e "chefe da família" contribui para reforçar a posição de liderança que os homens ocupam na hierarquia católica. Essa posição é legitimada por um discurso que atribui aos homens a missão sacerdotal sob a necessidade de valorização da tradição católica (JoÃo PAUlo II, 1994). No entanto, o catolicismo tem mudado especialmente com o surgimento da Renovação Carismática Católica, movimento que defende que leigos também podem ter acesso direto ao sagrado através dos dons do Espírito Santo (MACHAdo, 1996; MARIZ, 2003).

0 primeiro objetivo desse trabalho é, com base na análise da literatura sócio- antropológica sobre gênero e catolicismo, discutir hipóteses sobre mudanças da posição da mulher via movimento RCC. No entanto, realizei também coleta de dados empíricos ${ }^{1}$ baseada em análise dos sites do movimento carismático do Brasil e demais países da América do Sul (com exceção das Guianas). Essa análise tinha a finalidade de identificar os espaços de atuação e de atividades exercidas por mulheres para pensar, num primeiro momento, como elas estão inseridas no movimento carismático. Procurei contabilizar o número de homens e mulheres e seus cargos ou ministérios. Também tentei identificar, quando possível, se havia cargos específicos de mulheres.

Nesta análise, adoto o pressuposto de que as relações de gênero da sociedade mais ampla influenciariam a forma como as mulheres se inserem ou atuam nestes grupos. Pretendo verificar se a abertura que a RCC proporcionou aos leigos e leigas resultou em novos espaços de atuação especialmente para as mulheres. Sendo assim, o movimento carismático poderia estar influenciando a posição da mulher no catolicismo.

\section{Importância da RCC no cenário atual do catolicismo}

Ao reverem a história do Movimento de Renovação Carismática Católica e sua origem em encontros ecumênicos entre universitários protestantes pentecostais e católicos, os diversos trabalhos destacam que leigos (tantos homens como mulheres) eram responsáveis pela liderança do movimento em seu início. Mas pau-

\footnotetext{
${ }^{1}$ Esses dados faziam parte também de pesquisa de minha orientadora sobre RCC e novas comunidades na América Latina (pesquisa de Mariz ainda não publicada), projeto apoiado pelo CNPq.
} 
latinamente, o movimento foi colocado sob a orientação da estrutura eclesiástica (CARranza; Mariz, 2009). Diversos autores (como Prandi, 1997; Machado, 1996; CARranzA, 2000; entre outros) observam que o Movimento de Renovação Carismática contribuiu para o fortalecimento institucional da Igreja Católica. No entanto, a RCC tinha, quando surgiu e ainda hoje declara ter, a proposta de transformar a Igreja, "uma nova forma de ser Igreja" (MARIz, 2003) e assim transformar a forma de vivenciar o catolicismo para todos, incluindo laicato e clero.

Em fontes de pesquisa diversas ${ }^{2}$ e de divulgação sobre o movimento, é possível ter acesso a um breve histórico sobre o nascimento da Renovação Carismática. O movimento surge nos EUA a partir de um retiro espiritual, na Universidade de Duquesne em Pittsburgh, Pensilvânia, no ano de 1967. No Brasil, o movimento chegou em 1969, através de dois padres jesuítas, Haroldo Rahm e Eduardo Dougherty (CARranza, 2000).

Na base da organização estrutural da Renovação, estão os grupos de oração, sob a iniciativa e liderança de leigos (as). 0 caráter emotivo e espontâneo é o que diferencia os grupos de oração carismática de outros grupos da Igreja Católica. Seu público, em maioria, é representado por mulheres. Vários líderes de grupos criaram as chamadas novas comunidades, que possuem relativa autonomia e dinâmica própria.

No Brasil, grande parte destas novas comunidades surgiu nos meados das décadas de 90, com a proposta de retomar o ideário de vida cristã comunitária. Essas comunidades são fundadas por leigos (as) e/ou sacerdotes. As comunidades, em geral, exigem consagração, votos e obediência às regras específicas. São definidas como comunidades de vida e comunidades de aliança. Os membros das comunidades de vida apenas se dedicam à vida religiosa, as comunidades de aliança reúnem membros que possuem autonomia doméstica e material. Segundo Carranza e Mariz (2009), as razões pelas quais têm ocorrido o crescimento destas comunidades se devem à sua capacidade de oferecerem aos adeptos formas de consagração, que representam o elo identitário que une o grupo.

\footnotetext{
${ }^{2}$ As fontes de pesquisa citadas são os sites da RCC e das novas comunidades, onde são possíveis encontrar informações sobre a localização, atividades, lideranças, coordenações, dados sobre membros, informação sobre a história do movimento e fundadores, e também possui a função de evangelização e divulgação dos carismas das comunidades.
} 
A RCC se distingue de outros grupos e movimentos da Igreja Católica pela potencial autonomia de seus membros devido à possibilidade de todos terem experiência com os dons do Espírito Santo. Os “carismas" tanto dão poder aos leigos (as) como também explicam a variedade e pluralidade das novas comunidades, e dos grupos de oração (MARIz, 2003), e pela diversificação em torno de projetos e suborganizações que apresentam (CARRANZA, 2000). Por outro lado, em contraste com esse potencial de autonomia, o movimento de Renovação Carismática Católica resgata e reafirma os valores tradicionais católicos. Por um lado, a RCC inova em uma perspectiva autônoma e diversificada em relação ao catolicismo tradicional vivenciando uma diversidade de discursos e práticas, mas por outro lado, o movimento reforça a Igreja Católica cada vez mais se integrando à estrutura mais ampla da Igreja, e sob seu controle.

A RCC inova como um movimento que redefine o papel do (a) leigo (a), que são responsáveis por evangelizar e de transmitir e/ou retransmitir a tradição católica, além de se caracterizarem pelo contato direto com o sagrado oferecido pela experiência com os dons do Espírito Santo. A RCC aproxima homens e mulheres do sagrado e redefine a espiritualidade do católico, através da manifestação dos carismas e dons do Espírito Santo, que se exprimem na glossolalia, na cura, na exacerbação das emoções e no culto a Nossa Senhora.

\section{Mulheres na RCC e nas novas comunidades}

A bibliografia sobre catolicismo e gênero, como Theije (2002), Mariz e Machado (1997), Rosado Nunes (2009), entre outras, aponta que a mulher é maioria em quase todos os movimentos religiosos, embora em muitos ela não possa ser líder oficial da instituição - como o caso da Igreja Católica e outras igrejas cristãs. Como abordado por muitas autoras, entre essas Marjo de Theije (2002), a prática religiosa católica é mais forte entre as mulheres, sejam em grupos de oração carismática ou em outros movimentos leigos, as mulheres compõem $80 \%$ do público.

Sobre a maior propensão das mulheres à religião, Weber (1991 [1913]) apontava para uma tendência que as mulheres teriam para as religiões cristãs e especialmente para as religiões mais emocionais ${ }^{3}$. Para Linda Woodhead (2002), as mulhe-

\footnotetext{
${ }^{3}$ Weber destaca que no judaísmo e no islamismo esta tendência não ocorre da mesma forma que no cristianismo.
} 
res, na sociedade moderna, teriam uma maior participação nas religiões "tradicionais", religiões que reforçam, sobretudo, os valores domésticos e patriarcais, mas que também poderiam proporcionar a essas mulheres um espaço de atuação para além do doméstico. A religião, de certa forma, representa uma abertura à participação de mulheres nas instituições sociais e na vida pública.

A literatura socioantropológica analisada (MACHADO, 1996; MACHADO; MARIZ, 1997; ARY, 2000; Theije, 2002; CAmpos; CAMinha, 2009), que trabalha a questão da mulher no catolicismo, e tem como foco a presença de mulheres na RCC e nas novas comunidades, tem apontado para hipóteses de que o movimento carismático beneficia as mulheres no sentido de não apenas proporcionar espaços de atuação além do doméstico, mas também proporcionar apoio no enfrentamento de problemas cotidianos. 0 movimento carismático possui redes de solidariedade para os membros que vão de grupos mais informais até os mais institucionais, como os ministérios.

Apesar de serem dependentes de uma hierarquia, elas têm a possibilidade de estarem como liderança, tendo importante atuação. Isso pode trazer reconhecimento e empoderamento a estas mulheres. Em muitos casos, a Igreja ou grupo religioso se tornam um dos poucos espaços sociais em que elas estão inseridas. 0 reconhecimento e o empoderamento não significam total emancipação, mas podem levá-las a obter prestígio perante a família e a sociedade e uma revalorização de si mesma através das posições ou cargos ocupados. Assim, o engajamento em grupos religiosos é considerado uma atividade respeitável por elas (MACHADo, 1996).

A literatura também aponta para uma reafirmação da submissão da mulher no mundo católico, através da hipótese que estabelece uma relação entre Marianismo e a cultura machista da América Latina (Stevens, 1977). Assim, o Marianismo tem sido criticado como um conjunto de valores e crenças que dão significado espiritual ao sofrimento e à submissão das mulheres. É também interpretado como um contrapoder feminino, no sentido de que a imagem de inferioridade da mulher perante os homens é subvertida por meio de Maria.

No entanto, são valorizadas a submissão e a docilidade, esses valores seriam associados às mulheres em oposição aos atributos masculinos, como observado em interpretações de Evelyn Stevens (1977), Zaíra Ary (2000) e Maria das Dores Campos Machado (1996). Assim, o Marianismo normatizaria papéis para homens e mulheres cristãos e seria uma forma de demarcar os espaços reservados às mulheres, ou seja, as posições que podem ocupar na sociedade. 
A bibliografia tem mostrado que, de forma geral, as novas comunidades, em sua maioria, têm como fundadores homens. As mulheres destacam-se como conselheiras intelectuais e aparecem na história da fundação dessas comunidades como "cofundadoras", como no caso das Comunidades Shalom, uma das maiores comunidades do país fundada em Fortaleza em 1982, e a comunidade Obra de Maria, em Recife, reconhecida pela forte presença e atuação feminina. Nas comunidades, embora as mulheres se destaquem pela participação e liderança, o poder parece monopolizado pelos homens que são os fundadores e outras lideranças.

\section{Os sites da RCC em diferentes países da América do Sul}

Um dos trabalhos de referência mais importantes sobre a RCC na América Latina é o do padre dominicano, Edward L. Cleary (2011). Neste livro, Cleary destaca que os percentuais de carismáticos entre católicos de diferentes países da América do Sul são: Colômbia 28\%, Brasil 22\%, Argentina 14\%, Chile 14\%, Venezuela 14\%, Bolívia 12\%, Equador 10\%, Peru 10\%, Uruguai 8\% e Paraguai 2\% (BARRETT; JoHNson apud Cleary, 2011).

A pesquisa, nos sites da RCC de cada um dos países acima citados aponta para dados que revelam os espaços de atuação e de atividades exercidas pelas mulheres no movimento em cada país. Mostram que, na RCC do Chile, as mulheres estão presentes nas coordenações regionais do Centro e Norte do país, e ainda coordenam os grupos de oração de treze das vinte e três dioceses no país. Na Renovação Carismática Católica do Peru, mais especificamente em Lima, as mulheres ocupam a coordenadoria arquidiocesana, a secretaria e a tesouraria, coordenam vinte e uma das vinte e três regionais, e estão presentes nos ministérios, como: Cura, Primeiro Nível de Formação, Ensinamento, Acolhida, Ações Eclesiais, Ação de Recursos Econômicos, Família e Livraria. Dados do Censo Nacional da RCC do Peru de 2008 mostram que 79,18\% de seu público são mulheres.

Na RCC da Venezuela, as mulheres ocupam a coordenação nacional de dez das quinze dioceses. De dez ministérios, estão presentes liderando três, são eles: Serviço Social, Serviço de Comunidades e Ministério Infantil. O comitê nacional, que é composto pelos maiores cargos, como o de Coordenador Nacional, Assessor Nacional e Assessor Adjunto, tem como representantes homens, dois representantes do clero e um leigo. 
Na RCC do Brasil, as mulheres se fazem presentes nos ministérios nacionais, compondo a coordenação da Comunicação Social, o Ministério para as Crianças, Ministério para as Famílias, Promoção Humana, Religiosas e Consagradas e Formação, liderando seis de dezesseis ministérios. Na presidência estadual, estão presentes nos estados de Tocantins e Amazonas. Recentemente, mulheres ocuparam a presidência estadual nos estados do Mato Grosso e Paraná. Outro dado recente foi a eleição de uma mulher como presidenta nacional no período de 2013-2016².

No site RCC Equador, há informações sobre vinte e quatro comunidades, oito sob lideranças de mulheres, doze sob lideranças de homens e quatro são compartilhadas entre homens e mulheres. 0 ministério de "Promoção Humana e Ação Social" tem como líder uma mulher. Não há informações sobre outros ministérios e lideranças. 0 movimento no país se divide em cinco regiões, três são coordenadas por mulheres.

O movimento carismático na Argentina está subdividido em seis regiões: nordeste, noroeste, centro e litoral, Buenos Aires e Sul. Na região nordeste, o quadro de coordenação é composto por dois homens e duas mulheres. Nesta região, há nove grupos de oração e seis desses são coordenados por mulheres. Na região noroeste, a equipe responsável pela coordenação regional é composta por dois homens e duas mulheres. Sobre as coordenações das dioceses, há informações sobre duas, as dioceses de Inmaculada Concepcion de Tucuman, coordenada por uma mulher e a diocese de Santiago del Estero, que tem como coordenador um homem. Na região centro, a equipe regional é composta por três mulheres e um homem. Das dez dioceses que integram a região, sete são coordenadas por mulheres. Na diocese de Cruz Del Eje, as mulheres além de comporem a coordenação ocupam outros cargos como secretaria e tesouraria. Nas dioceses de San Luis e San Rafael, além da coordenação há mulheres na vice-coordenação. A equipe da região litorânea é composta somente por homens, nesta região há oito dioceses; na diocese de Concórdia, a equipe é composta por cinco mulheres e três homens. Na diocese de Rosario, há nove grupos de oração, sendo sete coordenados por mulheres e quatro coordenações compartilhadas por homens e mulheres, além de nove mulheres como vice-coordenadoras. A

\footnotetext{
${ }^{4}$ Atualmente, é a presidente da Arquidiocese de Vitória, no Espírito Santo. Além disso, ela exerce a função de primeira secretária do Conselho Nacional.
} 
equipe diocesana em Santa Fé é composta por cinco mulheres e um homem, sobre as demais dioceses não há informações disponíveis sobre lideranças.

A equipe da região de Buenos Aires é composta por treze mulheres e oito homens nas coordenadorias de dezenove dioceses e vicariatos. As informações sobre a região Sul mostram que há duas equipes de coordenação desta região, compostas por três mulheres e um homem. Sete dioceses integram esta região, mas há informações somente sobre três dioceses, são elas a de Neuquem, coordenada por uma mulher e tem como subcoordenadores seis mulheres e dois homens. Na diocese de Comodoro Rivadavia, um homem integra a coordenação, e em Rio Gallegos, uma mulher ocupa a coordenação.

Já na Colômbia, o país com maior proporção carismática entre os católicos, observou-se que entre os "miembros consejos nacional RCC" de 2009-2011, está o sacerdote Diego Jaramillo - assessor eclesiástico - e estão mais seis leigos, desses três homens e três mulheres. 0 movimento se divide em seis regiões; entre as dioceses de cada região se elege um representante regional, que integra o Conselho Nacional junto com o Sacerdote Assessor Nacional e o Coordenador Nacional da Secretaria de Jovens.

Da Bolívia, pesquisou-se o site da comunidade mais importante da RCC naquele país, La Mansion, e dos trinta grupos de oração lá listados, três são dirigidos por casal, treze por mulheres e quatorze por homens. 0 site da RCC do Paraguai era pouco elaborado e não havia nomes das lideranças. Não foi encontrado um site específico do movimento RCC no Uruguai.

Os dados acima mostram que, as mulheres na RCC e nas novas comunidades, comparadas aos homens, tendem a ocupar a maioria dos espaços sejam como membros, sejam até mesmo como líderes. Em alguns países, as mulheres apresentam uma participação em termos de liderança similar e, às vezes, maior que a dos homens. Deve-se levar em consideração que os dados são limitados e insuficientes. Em alguns países, não há informações sobre as lideranças nos sites da RCC e em outros não há número de membros. Houve caso de país onde não foi encontrado o site da RCC.

Na base do movimento, ou seja, nos grupos de oração, as lideranças são majoritariamente de mulheres. É possível, contudo, sugerir algumas conclusões a partir dos dados encontrados, como a de que atributos e valores femininos tendem a favorecer as experiências com o sagrado e o vínculo com os grupos religiosos. Neste 
sentido, as mulheres possuem atributos e subjetividades que as aproximariam da religião, e desta forma, a divisão de tarefas neste contexto religioso segue e reforça os estereótipos e papéis tradicionais relativos às mulheres.

Em países, como Peru, Venezuela, Brasil e Equador, as mulheres estão liderando ministérios que são associados ao "universo feminino" ou aproximado das mulheres por excelência, como: ministério de ensinamento, acolhida, serviço social ou ação social, ministério infantil ou para as crianças, ministério para as famílias e promoção humana.

Entretanto, foi notada a presença de mulheres no ministério de formação, no Brasil e Peru, que tem por objetivo formar as lideranças na RCC. Outra novidade é uma mulher como presidenta da RCC Brasil e também a eleição de uma mulher da Guatemala para presidir o Conselho Carismático Latino Americano (CONCCLAT).

Observando a distribuição dos cargos e ministérios da RCC, em alguns países, predominam padrões de comportamento influenciados por uma estrutura patriarcal, que eleva os homens a posições de mais status e poder. A análise dos sites indica que ocorre na RCC o mesmo que na maioria das religiões: os relativamente poucos homens que participam das atividades religiosas são mais frequentemente líderes. A autoridade e o prestígio que acompanham as lideranças estão, assim, mais próximos ao masculino.

\section{Conclusão}

Este estudo procurou, com base na análise da bibliografia sobre mulheres no catolicismo na América Latina, avaliar em que medida a RCC tem favorecido a maior presença das mulheres nos espaços de liderança religiosa católica. Essa discussão, sobre a posição da mulher no catolicismo, na RCC e novas comunidades tinha por objetivo analisar a possibilidade de alterações na posição da mulher no catolicismo a partir do crescimento do movimento carismático. A bibliografia sugere hipóteses de uma crescente presença de lideranças femininas. Esses dados, embora simples, sugerem que há uma presença significativa de mulheres, e às vezes maior do que de homens, em posição de liderança na RCC em vários países cujos sites foram analisados. No entanto, os dados são insuficientes para refletir a respeito de como as relações de gênero da sociedade em geral de cada país podem, de forma diferente, influenciar ou determinar a maneira como as mulheres se inserem ou atuam no movimento carismático. 
A literatura analisada mostra que, assim como ocorre na maior parte dos grupos religiosos brasileiros, a RCC destaca-se pela maior participação de mulheres. Por ser um movimento criado por leigas(os), resultou na criação de espaços de atuação e lideranças para homens e mulheres. Observa-se, no movimento como um todo, que as mulheres, mesmo sendo maioria, estão em alguns países relativamente em menor quantidade em posições de liderança, como no caso do Brasil, ou ocupando lideranças nas bases. No entanto, embora a RCC não defenda um discurso feminista, é notável a crescente presença de mulheres em cargos de liderança, como recentemente eleita a nova presidenta da RCC Brasil e a presidenta do CONCCLAT. Esses fatos podem representar indícios de futuras reflexões e mudanças no campo religioso em questão. No caso do Brasil, a mulher, na presidência geral da RCC Brasil, pode estar sinalizando para mudanças em curso na sociedade, uma mudança de fora para dentro, ou seja, da sociedade para a RCC. De todo jeito, a RCC tem se mostrado como um movimento que tem possibilitado maiores chances para mulheres se tornarem líderes quando comparado a outros espaços católicos.

\section{Páginas da internet pesquisadas:}

Comunidade Obra de Maria: <http://www.obrademaria.com.br/>.

Comunidade Shalom: <http://www.comshalom.org/>.

La Mansión: <http://www.lamansion.org/>.

RCC Argentina: < $\underline{\text { http://www.rcc-argentina.com.ar/>. }}$

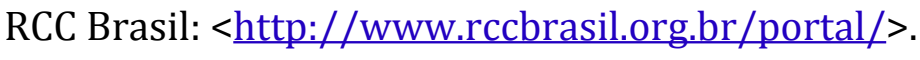

RCC Colômbia: <http://rcc-colombia.org/>

RCC Equador: <http://www.rccecuador.org/principal.html>.

RCC Lima (Peru): <http://www.rcclima.org.pe/la-rcc/quienes-somos.html>.

RCC Peru: <http://www.rccperu.org/>.

RCC Venezuela: <http://www.rccvenezuela.com/index.html>.

\section{Referências}

Ary, Z. (2000). Masculino e feminino no imaginário católico. São Paulo, Annablume. 
Bidegain, A. M. (1996). Mulheres: autonomia e controle religioso na América Latina. Petrópolis, Cehila.

Campos, R. B. C.; Caminha, C. P. R. (2009). "A obra de Maria: a redefinição da devoção mariana”. In: CARranzA, B.; MARIZ, C. L.; CAMURÇA, M. (Org.). Novas comunidades católicas: em busca do espaço pós-moderno. Aparecida, Ideias \& Letras, p. 267- 288.

Carranza, B. (2000). Renovação Carismática Católica. Aparecida, Ed. Santuário.

CARranza, B.; MARIZ, C. L. (2009). "Novas comunidades católicas: por que crescem?”. In: CarranzA, B.; Mariz, C. L.; CAmurÇA, M. (Org.). Novas comunidades católicas: em busca do espaço pós-moderno. Aparecida, Ideias \& Letras, p. 139-170.

CleARY, E. L. (2011). The rise of charismatic catholicism in Latin America. Gainesvile, University Press of Florida.

JoÃo PAulo II (1994). Ordinato sacerdotalis. Disponível em: <http://www.vatican. va/phome po.htm>.

Machado, M. D. C. (1996). Carismáticos e pentecostais - adesão religiosa na esfera familiar. Campinas, Autores associados.

MACHADo, M. D. C. ; MARIZ, C. L. (1997). "Mulheres e práticas religiosas - um estudo comparativo das CEBs, comunidades carismáticas e pentecostais". Revista brasileira de Ciências Sociais, São Paulo, v. 34, p. 71-87.

MARIZ, C. L. (2003). “A Renovação Carismática Católica: uma igreja dentro da igreja?”. Civitas, Porto Alegre, v. 3, n 1, p. 169-186.

MARIZ, C. L.; LopeS, P. V. L. (2009). “O reavivamento católico no Brasil e o caso da Toca de Assis”. In: Teixeira, F.; Meneses, R. (Org.). Catolicismo plural: dinâmicas contemporâneas. Petrópolis, Vozes, p. 75-108.

Prandi, R. (1997). Um sopro do Espírito. São Paulo, Edusp.

Rosado Nunes, M. J. F. (2009). “Religiões”. In: Hirata, H.; Laborie, F.; DoARÉ, H.; Senotier, D. (Org.). Dicionário crítico do feminismo. São Paulo, Ed. UNESP, p. 213-217.

SouzA, S. D. (2006). Gênero e religião no Brasil. São Bernardo do Campo, Ed. Universidade Metodista de São Paulo.

STEVens, E. P. (1977). "Marianismo: la otra cara del machismo em Latino-America". In: Pescatelo, A. Hembra y macho in Latino-America: ensaios. México, Ed Diana.

FERNANDES, S. R. (2005). “A não ordenação feminina: delimitando as assimetrias de gênero na igreja católica a partir de rapazes e moças vocacionados/as". Estudos feministas, v. 13, p. 425-436. 
Theije, M. (2002). “'São metade macho, metade fêmea': sobre a identidade de gênero dos homens católicos”. AntHropológicas, v. 13(1), p. 47-56.

WEBER, M. (1991 [1913]). Economia e sociedade: fundamentos da sociologia compreensiva. Brasília, Ed. UnB, p. 332-336.

WoodHEAD, L. (2002). "Mulheres e gênero: uma estrutura teórica”. Revista de estudos da religião, $\mathrm{n}^{\circ} 1$, p. 1-11.

Recebido em dezembro/2012

Aprovado em fevereiro/2013 